\title{
EFFECT OF DIFFERENT ROLL FORMING PROCESSES ON MATERIAL PROPERTIES OF SQUARE TUBES
}

\author{
Fei Han *, Yun Wang, Tao Zhang, Qian Li and Yu Song \\ School of Mechancial and Materials Engineeing, North China University of Technology, Beijing, 100144, China \\ * (Corresponding author: E-mail: hanfei@ncut.edu.cn)
}

\section{A B S T R A C T}

Different roll forming processes result in parts with different properties. This study compared the behavior of square tubes manufactured using two different processes, namely continuous and direct forming process, and then examined the yield strength, ultimate strength, residual stress, and metallography in different regions. Furthermore, finite element models of direct and continuous forming were developed, and the results obtained using these models agreed well with the experimental results. The yield and ultimate strengths of each part of the continuously formed square tube were higher than those of the directly formed square tube. The residual stress showed that different processes considerably affected the longitudinal residual stress but had a less significant effect on the horizontal residual stress. The residual stress due to continuous forming was higher than that due to direct forming. Microscopic tests showed that the weld seam of the continuously formed square tube exhibited greater plasticity and anti-impact toughness than that of the directly formed square tube. This study can serve as a guide to practical production and suitable process selection.

\section{A R T I C L E H I S T O R Y}

\begin{tabular}{|c|c|}
\hline Received: & 13 January 2020 \\
\hline Revised & 26 April 2020 \\
\hline Accepted & 30 April 202 \\
\hline
\end{tabular}

K E Y W O R D S

Roll forming;

Material property;

Residual stress;

Metallography

\section{Introduction}

Square tubes are widely used, especially in the construction industry, because they use less base material and have low energy consumption, high production efficiency, and high quality. Two manufacturing methods are commonly used for square tubes: direct and continuous forming. In direct forming, the sheet is directly roll-formed into an open rectangular part, and the edges are then welded to form the final closed rectangular tube. In continuous forming, the sheet is first roll-formed into a round tube, the edges are then welded to form a closed round profile, and the round tube is flattened to form the final closed rectangular tube.

The behavior of square and rectangular tubes is different from that of base materials. Cold forming of steel sheets produces work-hardening effects. Thus, the material properties such as yield and ultimate strengths are all locally affected by a degree that depends on the bending situation. Different forming processes have different effects on the material properties, metallography, and residual stresses in the flat, corner, and welding seam regions, which can have a significant effect on the quality. For safe use and accurate predictions, many researchers have studied the material properties and residual stress of the complete cross section and in each region. Huang [1] conducted a large number of tensile tests on several groups of carbon steel, stainless steel, and alloy steel after cold roll forming. Using quasi-static tensile and dynamic tensile tests, the static and dynamic tensile stress-strain curves were obtained at different rates. In addition, the specific steps of the tensile experiment were summarized to provide a reference for other similar experiments. Kohar et al. [2] studied the influence of the elastic-plastic behavior of a square tube material on steady crushing force, peak crush force, energy absorption, and crushing effect of square tube axial crushing. Different processes result in different material properties, and different deformation histories can cause different work hardening in each part of the tube. Hu et al. [3] tested the material properties of various parts of the same type of a processed square tube. Sun and Packer [4] found that the effects of cold forming indicated that no clear yield point could be obtained. Li et al. [5] found that the yield strength of flat coupons had a greater effect on local buckling than that of the corner coupons. Li and Young [6] conducted tensile tests on roll-formed high-strength steel. In their study, the material properties were studied under high-temperature conditions, and a new curve for the material properties was proposed.

Davani et al. [7] demonstrated that the microstructure significantly affected the mechanical properties, and it could be confirmed using the material properties. Pham and Kim [8] found that the grain size, shape, and orientation had significant effect on the hardness of the phases. Luo et al. [9] investigated the evolution of microstructures and mechanical properties and discussed the formation mechanism of titanium oxides. Miura et al. [10] found that the increased hardness was caused by grain refinement and the formation of martensite.

Manufacturing processes lead to residual stresses in the specimens. These residual stresses usually exert a negative effect on their performance [11]. The roll-forming process is well known to possibly result in a high residual stress in its products, and this residual stress is one of the main factors affecting the bearing capacity of steel members [12]. In addition, residual stress can also affect the rate of crack propagation, which can lead to a shorter fatigue life [13]. Ma et al. [14] studied cold roll forming of high-strength hollow steel sections. $\mathrm{Li}$ et al. [15] studied the longitudinal residual stresses of annealed and nonannealed steel tubes with square and rectangular hollow sections which are coldformed and thick-walled. The effects of process parameters such as thickness, depth-to-thickness ratio, and the yield strength of a flat plate on the residual stress are analyzed. Using extensive tensile tests, the effect of cold roll forming was studied, the residual stress in three regions was measured, and a new type of high-strength steel-structure model, which correlated well with the experimental results, was proposed. Liu and Chung [16] proposed a finite element model that could effectively predict the residual stress distribution after welding. Yao et al. [17] proposed a finite element-based method to predict the equivalent plastic strain and residual stress in the square, rectangular, and elliptical hollow sections of cold-formed steel, which include normal-grade and high-strength steel.

In addition to the experiments, the different behavior, material properties, and residual stresses in different regions have been explored using finite element analysis (FEA). Wen and Pick [18] investigated the edge buckling of ERW pipes using FEA. Their results showed that edge buckling could be prevented by setting the machine parameters, such as the roll gaps. Li et al. [19] set up a FEA model to simulate different processes and found different residual stress distributions and magnitudes. Some researchers have ignored the differences in the material behavior in corner and flat regions when establishing the FEA models [20]. However, Yuan et al. [21] built a more detailed model that considered the effects of geometric imperfections and residual welding stress. Thus, details from various parts of the model were required. In addition, Yang et al. [22] proposed an analytical model to determine the effect of friction on the tube forming process and final thickness distribution along the tube section.

Most of these investigations were mainly concerned with the material properties and residual stress of complete cross sections and each region. These methods ensured reliability in the engineering perspective but did not consider the forming effect or combine the results with microstructure analysis to explain the deformation mechanism. Square tubes formed using different processes have different plastic strain histories. This can lead to differences in the material properties, microstructure, and residual stress, which can affect the performance of the product.

In this study, the aim is to improve the understanding of the material properties, microstructure and residual stress of the two square tube forming processes. Macro and micro experiments were conducted to investigate the material properties observed. A quasi-static tensile test, experiments concerning the metallography, and residual stress tests were performed. Finally, FEA was carried out and then verified using the experimental data. The results of the 
experiments and simulations were compared, and the mechanism underlying the changes in the material properties of square and rectangular tubes under different processes was investigated.

\section{Experiment and FEA}

\subsection{Tensile Test}

Fig. 1 shows that the strain value was obtained using an optical measurement system (ARAMIS, GOM). The specimens were prepared and tested according to the Chinese Metallic Materials-Tensile Testing standard (GB/T228-2002) using an MTS displacement sensor. The chemical composition of Q235 steel is listed in Table 1.

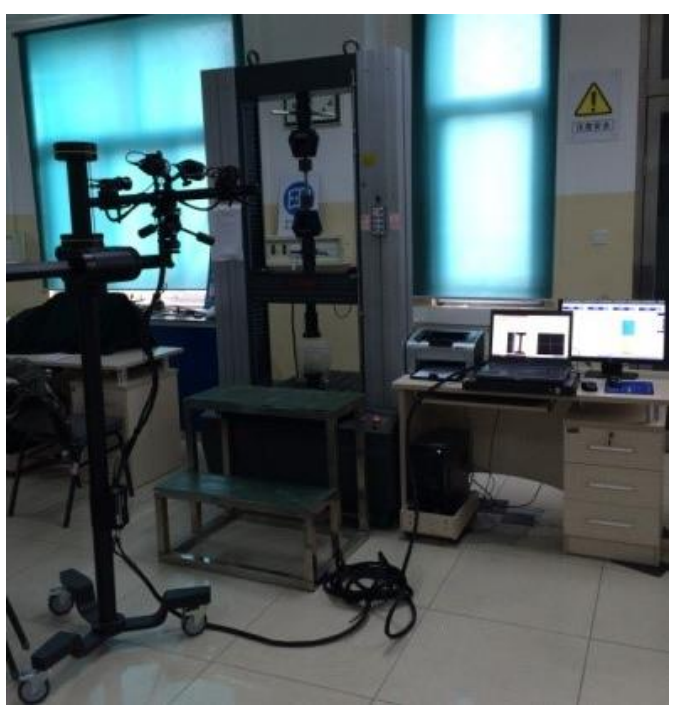

Fig. 1 Experimental test

Table 1

Chemical composition of Q235 steel (wt\%)

\begin{tabular}{cccccccc}
\hline $\mathrm{C}$ & $\mathrm{Si}$ & $\mathrm{Mn}$ & $\mathrm{S}$ & $\mathrm{P}$ & $\mathrm{Cr}$ & $\mathrm{Ni}$ & $\mathrm{Cu}$ \\
\hline 0.16 & 0.21 & 0.5 & 0.034 & 0.027 & 0.18 & 0.26 & 0.19 \\
\hline
\end{tabular}

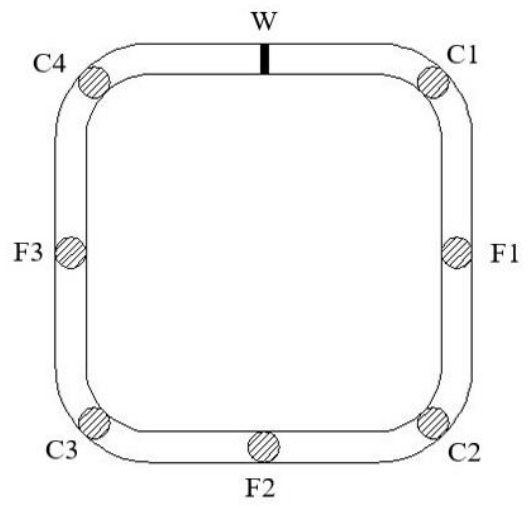

Fig. 2 Sampling positions and labeling

Fig. 2 shows that two tensile specimens were taken from the corners, i.e., flat and welding seam regions in each square tube. The schematic diagram of the flat specimen is shown in Fig. 3(a) in which gauge length of the specimen $L_{0}$ was $55 \mathrm{~mm}$ and length of the parallel segment $L c$ was $95 \mathrm{~mm}$. Fig. 3(b) shows the schematic diagram of the round-corner specimen where the gauge section length of the specimen was $40 \mathrm{~mm}$, the length of the parallel segment was 80 $\mathrm{mm}$, and total length $L t$ of both specimens was $200 \mathrm{~mm}$. Fig. 3(c) shows the position of the rounded specimen end in the square tube section, where $B 1$ denotes the linear distance between the tangent points of the outer surface of the round corner of the square tube. Fig. 3(d) shows the position of the rounded specimen gauge section in the square tube section, where $B 2$ is the width of the gauge section, which represented the linear distance between the tangent points of the inner surface of the round corner of the square tube.

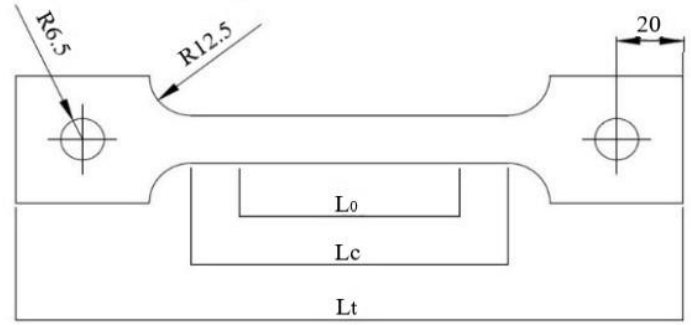

(a) Plate specimen

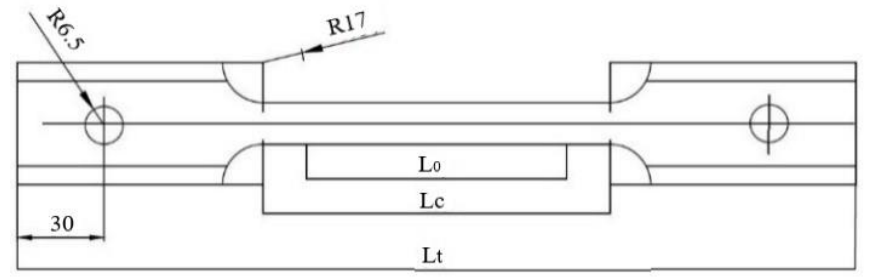

(b) Round specimen

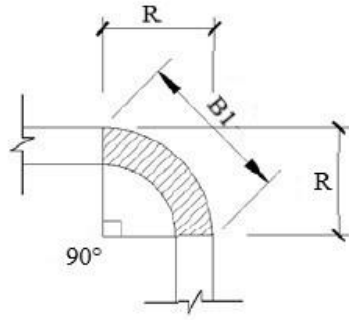

(c)

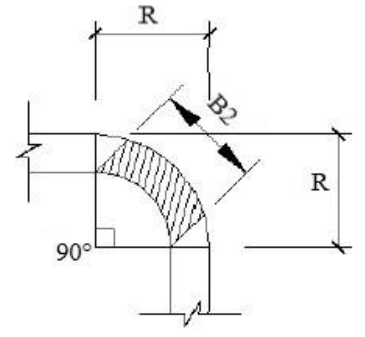

(d)
Fig. 3 Specimen size and sampling position

\subsection{Design of the Flower Diagram and Finite element Simulation}

The flowers for the direct and continuous forming are shown in Fig. 4. In the direct forming process, the bending corner was formed from the outside to the inside, and finally, welding was performed. In the continuous forming process, a round tube was formed, welded, and then shaped into a square tube.

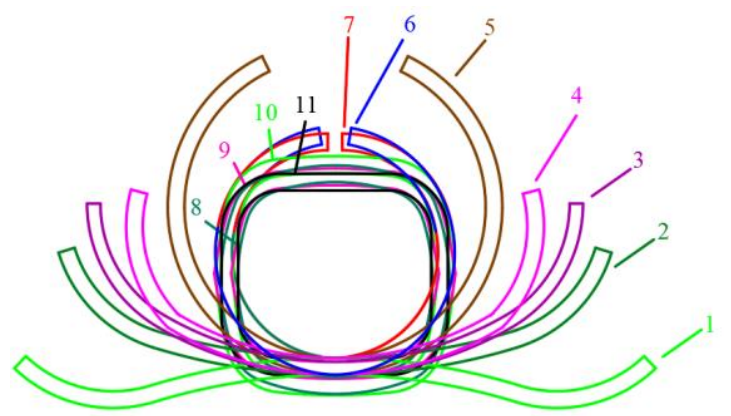

(a) Forming flower at continuous forming

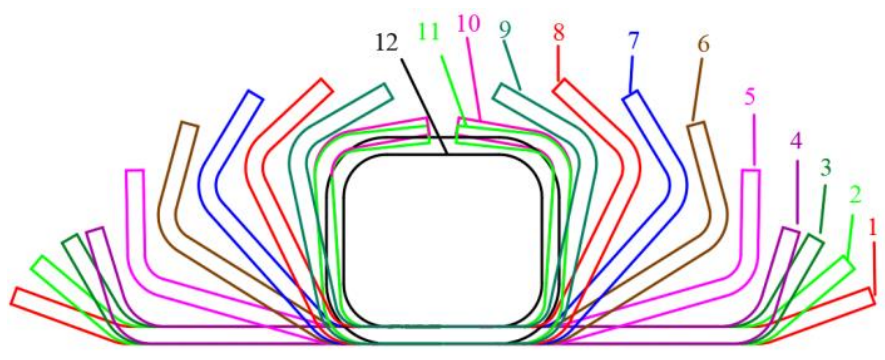

(b) Forming flower at direct forming

Fig. 4 Forming flowers for direct and continuous forming

A typical component with the final shape of a square rectangular tube is shown in Fig. 5. The components used in this study were made from Q235 steel, and its material properties are shown in Fig. 6. 
The finite element model of the direct and continuous forming were established in ABAQUS/Explicit, and the mesh type of the component was S4R.
The two assembly processes are shown in Fig. 7.

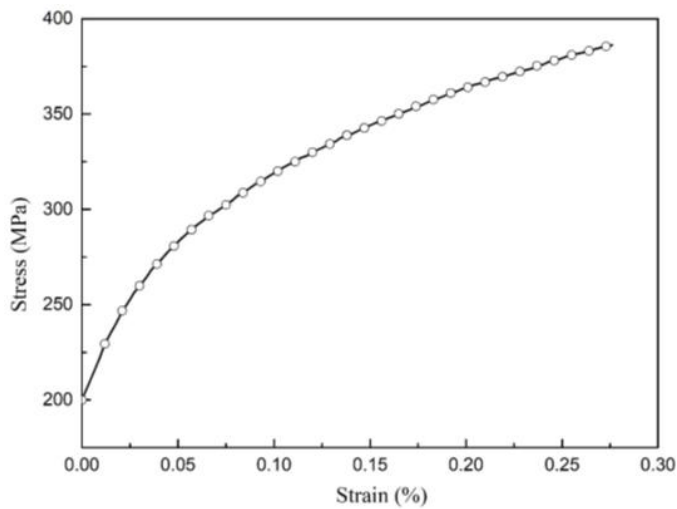

Fig. 6 True stress-plastic strain diagram for Q235 steel

Fig. 5 Geometric dimensions of the specimen

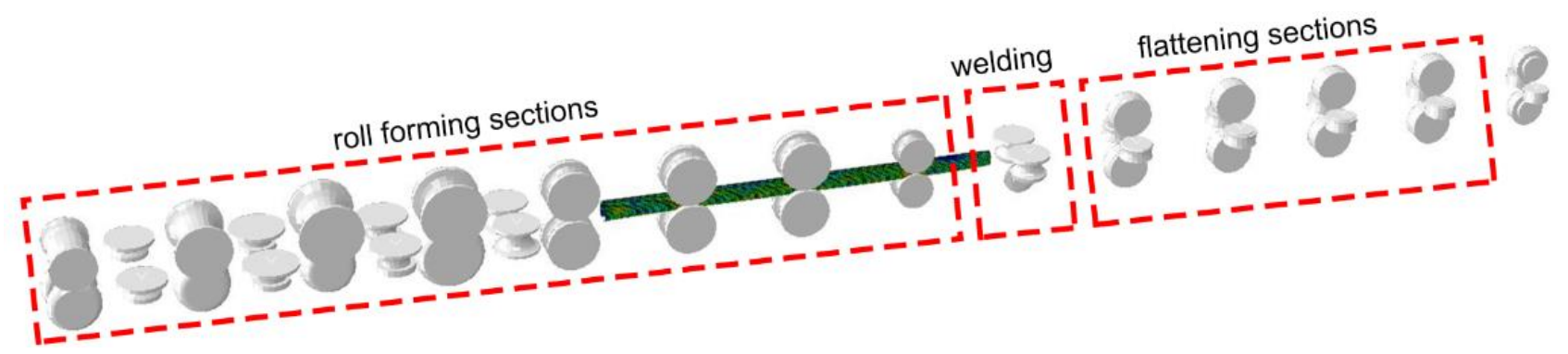

(a) Continuous forming

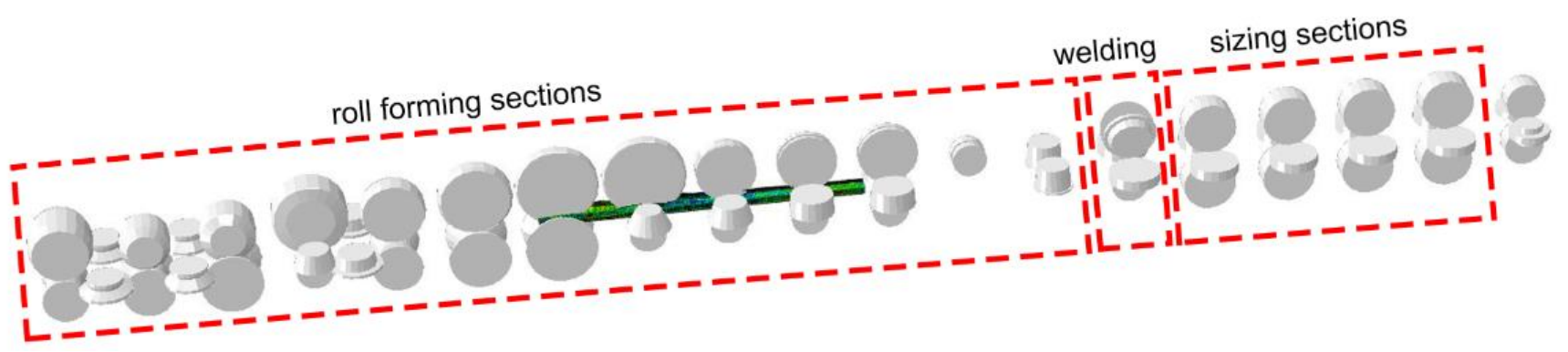

(b) Direct forming

Fig. 7 FEA model of the different roll forming processes

\section{Results and discussion}

\subsection{Differences in Material Properties Between the Two Processes}

A summary of the obtained material properties is listed in Table $2 . \mathrm{RP}_{0.2}$ indicates the average yield strength, and $R m$ is the average ultimate strength. Coefficients $\rho 1$ and $\rho 2$ are the ratios of the yield strength of the flat and corner regions to that of the base material, respectively, whereas $\rho 3$ and $\rho 4$ denote the ratios of the ultimate strength of the flat and corner regions to that of the base material, respectively.

According to the previously designed dimensions of the flat and corner tensile test specimens, the position and shape of the specimens after the tensile fracture are shown in Fig. 8. The material properties significantly vary throughout the square tube. In the same tube, the corner material has a higher degree of work hardening than the flat material. $\mathrm{Li}$ [5] found that the strain could reach or exceed the yield strain of the flat specimens, which means that the sections become plastic when local buckling occurs. Different forming processes result in different material properties, and different deformation histories cause different work hardening in each part of the square tube. Shengde $\mathrm{Hu}$ tested the material properties of various parts of square tubes processed using the same method and found that the material properties in the flat and corner regions were different [3]. To investigate the effects of different forming processes on the material properties, a tensile test was performed on various parts of the square tubes that were processed using different techniques.

Stress-strain curves in the different regions of the square tube are obtained, and some of these curves are shown in Fig. 9. The repeated experiments demonstrate a high degree of data coincidence, which validate the reliability of the experiment. For each type of square tube, two base materials are considered for comparative experiments.
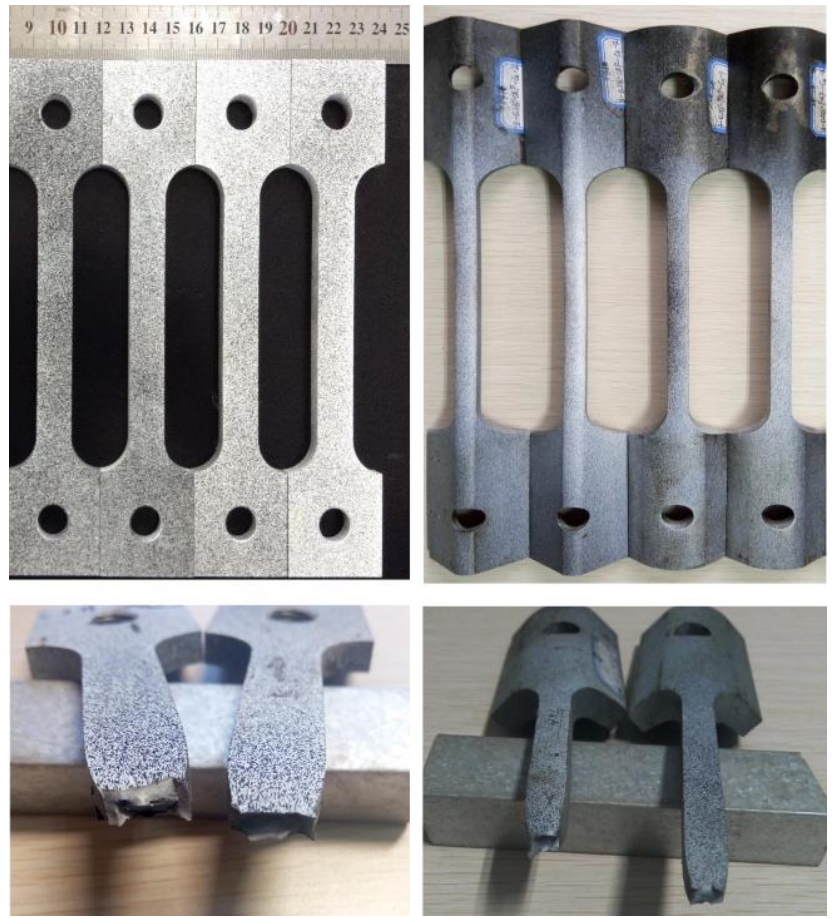
Table 2

Material properties

\begin{tabular}{ccccccc}
\hline Process & Position & $\mathrm{RP}_{0.2}$ & $\mathrm{Rm}$ & $\rho 1$ & $\rho 2$ & $\rho 3$ \\
\hline \multirow{3}{*}{ Continuous forming } & Flat & 375 & 430 & & & \\
& Welding & 524 & 548 & 1.16 & 1.34 & 1.11 \\
& Corner & 503 & 543 & & 1.27 \\
\hline \multirow{2}{*}{ Derect forming } & Flat & 312 & 395 & 1.03 & 1.07 \\
& Welding & 466 & 519 & & 1.29 \\
\hline
\end{tabular}

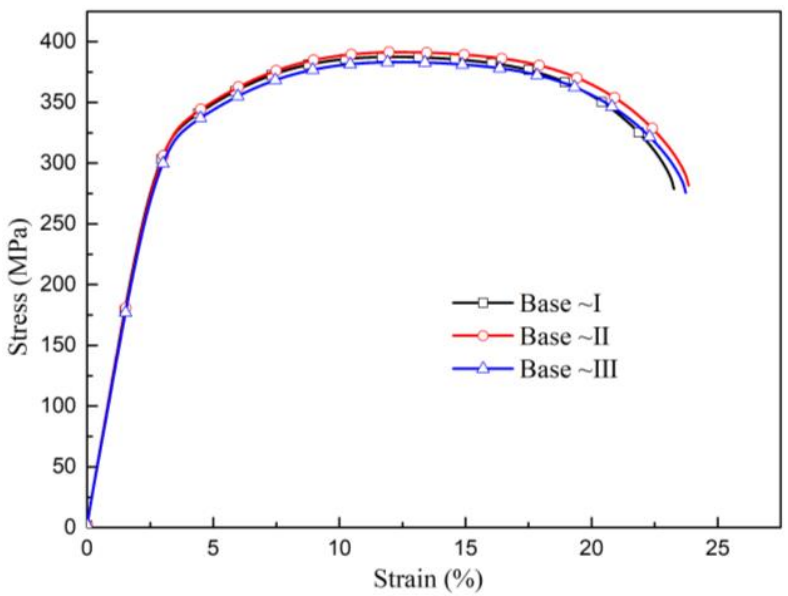

(a) Base material

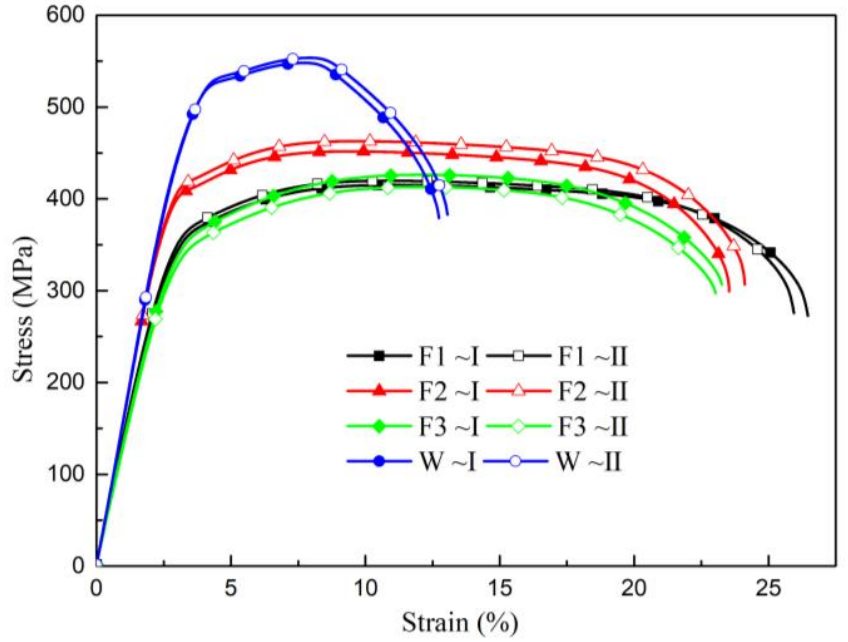

(b) Flat and weld of continuous forming

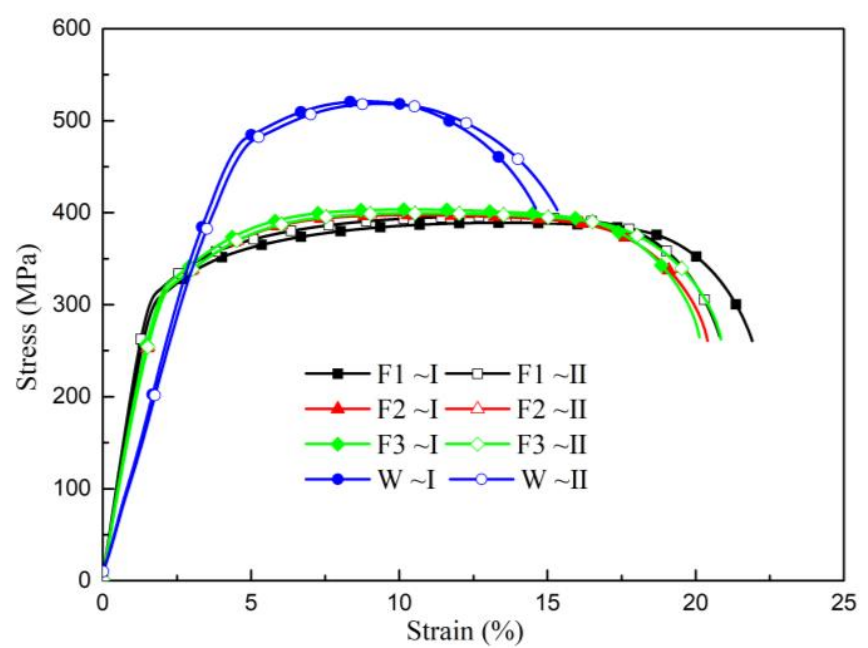

(d) Flat and weld of direct forming

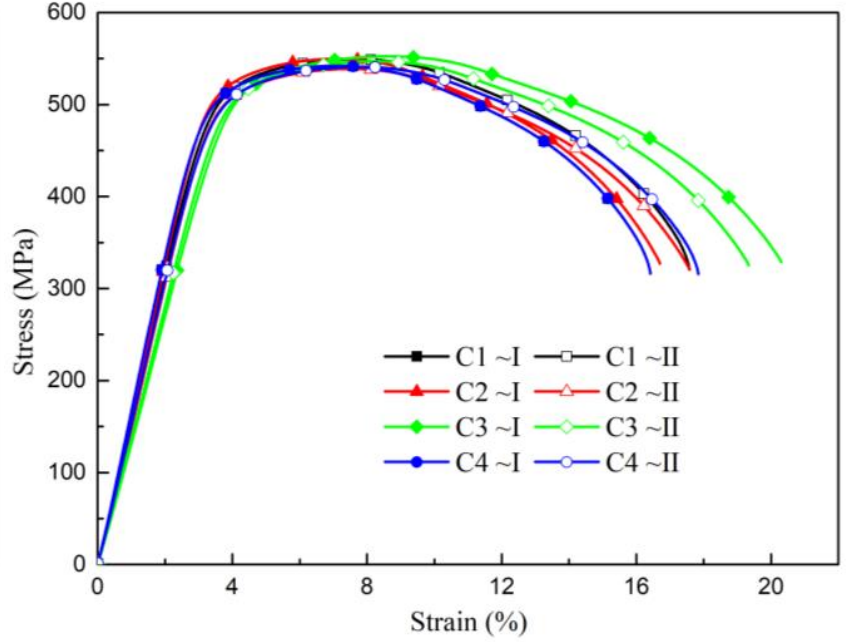

(c) Corner of continuous forming

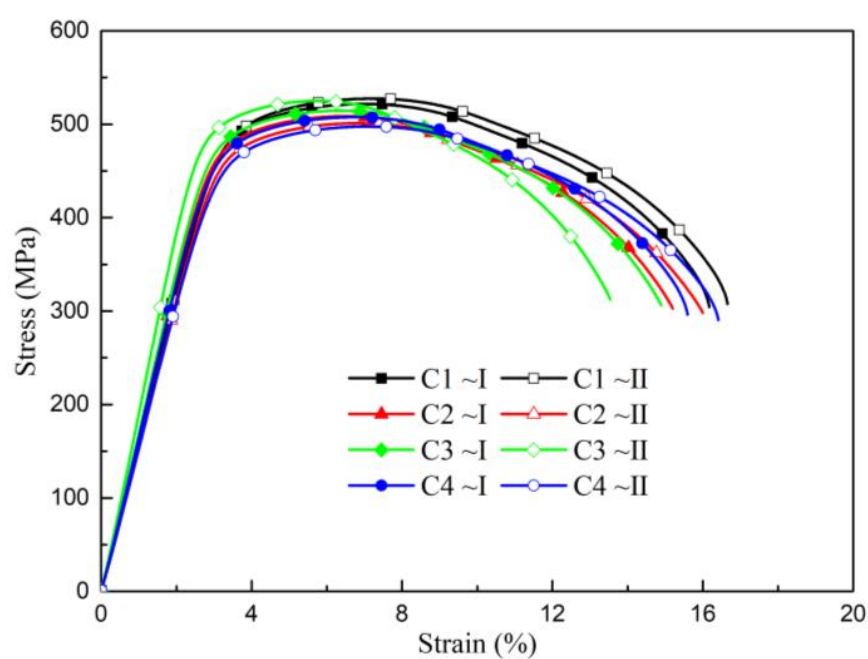

(e) Corner of direct forming

Fig. 9 Stress-strain curve in the different regions of the square tube 
mechanical properties of the base material and the flat part of direct forming are basically the same, which is similar to the curve in Fig. 9(b), although with a slight difference. The reason is that in the continuous forming process, the flat part is first bent and then reshaped, which is different from direct forming, resulting in a change in the mechanical properties of the plate. Comparing the flat region and the corner region of the two forming processes, it is observed that the deformation in the corner region is larger than that in the flat region during the forming process, which results in a large difference in the yield and ultimate strengths of the material. The yield and ultimate strengths obtained by continuous forming are slightly larger than those obtained by direct forming. The yield and ultimate strengths of the four corner regions of the square tube in the same forming process exhibit small fluctuations, which is closely related to the deformation of the four corner regions during the forming process

However, in the roll formed square tube, the yielding platform of the material from the flat region becomes shorter or disappears, whereas no yielding platform is present in the material collected from the corner region. This result shows that the crystal structure of the base material is destroyed during the forming process, which then recombines into a new crystal structure. In addition, it changes the mechanical properties of the material. The yield strength of the flat plate opposite the weld seam is higher than that on either side, indicating that the different forming processes exert a certain influence on the materialperformance parameters. The deformation is larger on the side opposite the weld seam; hence, it exhibits the largest yield strength. Because of the joint action of the solder and high temperatures at the weld, the yield and ultimate strengths increase significantly.

As shown by the lists in Tables 3 and 4, the yield and ultimate strengths in each region are higher in the continuously formed square tube than in the directly formed square tube. The relative increase in the yield strength is largest at F2 in the continuously formed tube because it has the largest relative deformation. The increase in the yield strength at the welding seam in the continuously formed tube is higher than that in the directly formed tube.

Table 3

Yield strength following the different processes

\begin{tabular}{|c|c|c|c|c|c|c|c|c|}
\hline Position & $\mathrm{F} 1$ & $\mathrm{~F} 2$ & F3 & $\mathrm{W}$ & $\mathrm{C} 1$ & $\mathrm{C} 2$ & $\mathrm{C} 3$ & $\mathrm{C} 4$ \\
\hline Continuous forming / $\mathrm{MPa}$ & 358 & 411 & 356 & 524 & 500 & 496 & 514 & 503 \\
\hline Direct forming / MPa & 309 & 321 & 305 & 466 & 480 & 469 & 485 & 460 \\
\hline Coefficient & 1.16 & 1.28 & 1.17 & 1.12 & 1.04 & 1.06 & 1.06 & 1.09 \\
\hline
\end{tabular}

Table 4

Ultimate strength following the different processes

\begin{tabular}{|c|c|c|c|c|c|c|c|c|}
\hline Position & F1 & $\mathrm{F} 2$ & F3 & W & $\mathrm{C} 1$ & $\mathrm{C} 2$ & $\mathrm{C} 3$ & $\mathrm{C} 4$ \\
\hline Continuous forming / $\mathrm{MPa}$ & 416 & 455 & 418 & 548 & 544 & 543 & 546 & 540 \\
\hline Direct forming / $\mathrm{MPa}$ & 391 & 394 & 399 & 519 & 524 & 504 & 519 & 502 \\
\hline Coefficient & 1.06 & 1.15 & 1.05 & 1.06 & 1.04 & 1.08 & 1.05 & 1.08 \\
\hline
\end{tabular}

*"Coefficient" refers to the ultimate strength ratio of the continuous to the direct forming.

Table 5

Specimen elongation after fracture

\begin{tabular}{|c|c|c|c|c|c|}
\hline Process & Position & $S_{A}(\%)$ & $S_{B}(\%)$ & $\bar{S}(\%)$ & $\bar{S}_{S}(\%)$ \\
\hline \multirow{9}{*}{ Continuous forming } & Base material & 31.72 & 32.20 & 31.96 & 31.96 \\
\hline & Flat F1 & 25.81 & 24.18 & 24.99 & \multirow{3}{*}{23.96} \\
\hline & Flat F2 & 20.87 & 22.53 & 21.70 & \\
\hline & Flat F3 & 25.45 & 24.90 & 25.18 & \\
\hline & Flat W & 15.45 & 12.90 & 14.18 & 14.18 \\
\hline & Corner $\mathrm{C} 1$ & 15.76 & 16.25 & 16.01 & \multirow{4}{*}{16.91} \\
\hline & Corner $\mathrm{C} 2$ & 17.88 & 19.67 & 18.78 & \\
\hline & Corner C3 & 15.76 & 15.44 & 15.60 & \\
\hline & CornerC4 & 16.57 & 17.89 & 17.23 & \\
\hline \multirow{9}{*}{ Direct forming } & Base material & 32.39 & 35.63 & 34.01 & \multirow[t]{2}{*}{34.01} \\
\hline & Flat F1 & 21.99 & 22.43 & 22.21 & \\
\hline & Flat F2 & 23.87 & 20.56 & 22.22 & \multirow[t]{2}{*}{21.96} \\
\hline & Flat F3 & 21.18 & 21.71 & 21.45 & \\
\hline & Flat W & 14.19 & 12.77 & 13.48 & 13.48 \\
\hline & Corner $\mathrm{C} 1$ & 14.91 & 15.51 & 15.21 & \multirow{4}{*}{15.25} \\
\hline & Corner C2 & 17.89 & 14.31 & 16.1 & \\
\hline & Corner C3 & 14.49 & 14.35 & 14.42 & \\
\hline & Corner C4 & 13.26 & 17.25 & 15.26 & \\
\hline
\end{tabular}

Elongation is an important index for measuring the material plasticity. In this experiment, the gauge section length before and after the fracture of all the specimens are measured, and the elongation after fracture of each specimen is then obtained according to the elongation formula. The experimental data are listed in Table 5. $S_{A}$ and $S_{B}$ are the measured values of the elongation of test specimens A and B (repeated test specimens), respectively. $\bar{S}$ is the average elongation of the repeated specimens. $\bar{S}_{S}$ is the average elongation at the same sampling position (flat or round corner) of the cross section.

The base material exhibits the highest elongation than the other parts of the square tube. The elongation of the flat specimen is close to that of the base material because the compressive deformation of the flat specimen is small during the forming process of the square tube and the effect of the roll forming is not obvious. However, because the rounded corners are greatly affected by the roll forming effect and the flat plates at the welds are subjected to high temperature, their elongation is relatively lower than that of the base material.

The plastic strain causes improvements in the yield and ultimate strengths. The strain history obtained from the FEA model confirms the above-described behavior. Fig. 10(a) shows that at the corner of the square tube, i.e., C2, the 
different deformation histories indicate that the tubes manufactured using the two processes exhibit significantly different plastic-strain histories. The continuously formed square tube experiences plastic strain during the forming of the round tube in the first station, and the strain change is more evenly distributed throughout the entire process. Conversely, during the direct forming, only certain stations experience deformation; thus, the curve suddenly increases. However, the final strains are similar, resulting in similar improvements in the material performance, which is consistent with the results of the tensile test.

Fig. 10(b) shows that at the flat part of square tube F2, the strain history shows that almost no plastic behavior can be observed at position F1 during the direct forming. However, obvious plastic behavior appears in the flat region because the flat material also participates in the deformation during the continuous forming but does not participate during the direct forming. The different strain values explain the differences in the behavior of the material properties of the specimens manufactured using the two processes.

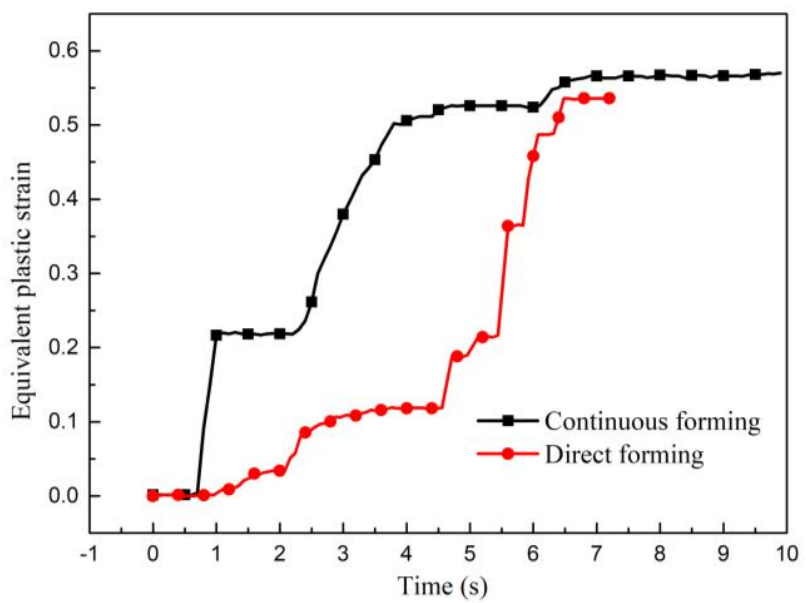

(a) At the corner of the tubes

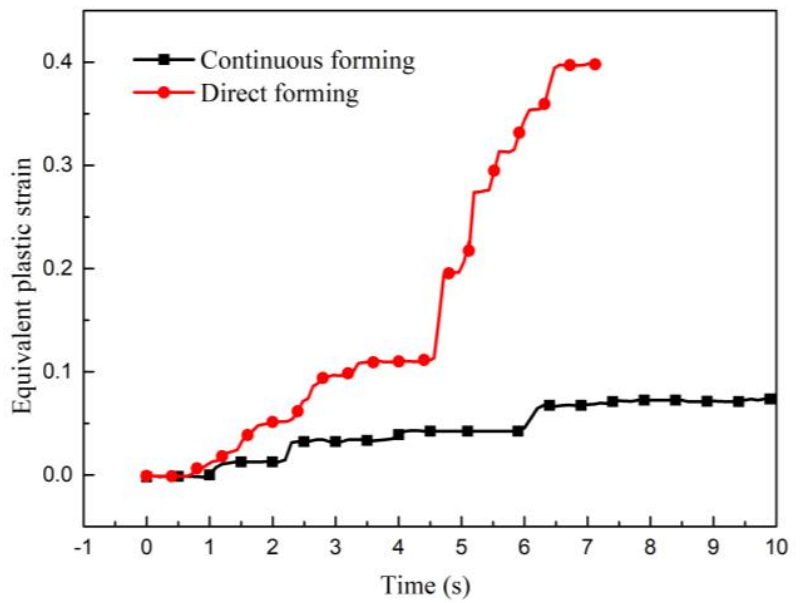

(b) At the flat region of the tubes

Fig. 10 Comparison of the equivalent plastic strain of the tubes manufactured using direct and continuous forming

The material properties can also be explained by the metallographic distribution [23]. For the characterization, the microstructure specimens are taken from the flat, corner, and welded-joint regions. The specimens are ground using abrasive paper, polished, and then etched using $4 \%$ nitric-acid alcohol solution. An OLYMPUS OLES4100 light microscope is used to extract the morphological parameters. Fig. 11 shows the microstructure (200x magnification) of the flat and corner regions in the tubes manufactured using different techniques. (a) shows the flat regions of the continuously formed tube, (b) shows the flat regions of the directly formed tube, (c) shows the corner regions of the continuously formed tube, and (d) shows the corner regions of the directly formed tube. The crystal structure is observed using the microscope and shows that the continuously formed tube illustrates the behavior of smaller grains and little austenite.

Fig. 11 shows that the metallographic structures of the two forming processes are similar, and the distribution of ferrite and pearlite is relatively uniform. The average ferrite diameter in the flat regions is measured, and the average grain diameter of the two processed square tubes is shown in Fig. 12. The ferrite diameters are denoted as D1 in the directly formed tube and D2 in the continuously formed tube. The continuously formed square tube has a smaller crystal grain size, and the macroscopic aspect shows that the yield and ultimate strengths in the flat region of the continuously formed square tube are larger.

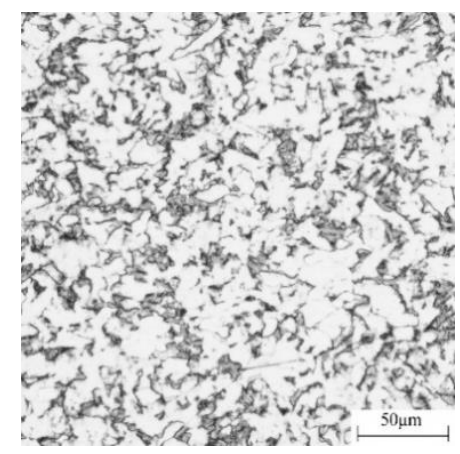

(a) Continuously formed tube $\mathrm{F}$

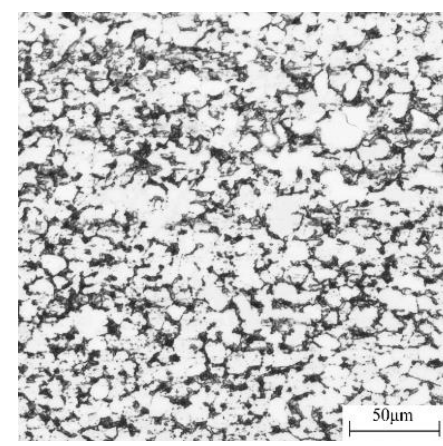

(c) Continuously formed tube $\mathrm{Cl}$

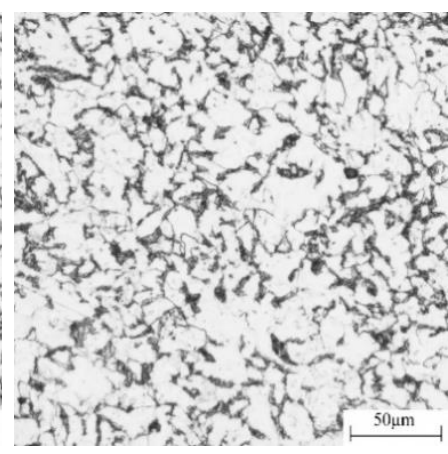

(b) Directly formed tube F

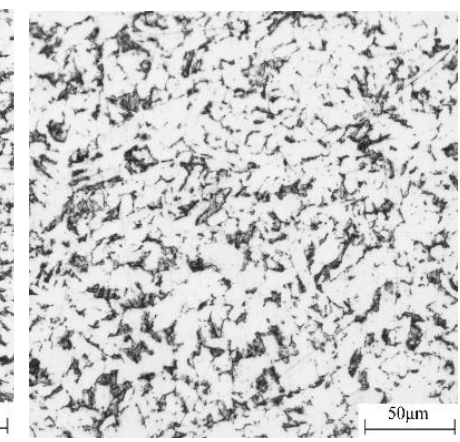

(d) Directly formed tube $\mathrm{C} 1$

Fig. 11 Microstructure of the flat and corner regions of the tubes manufactured using different techniques

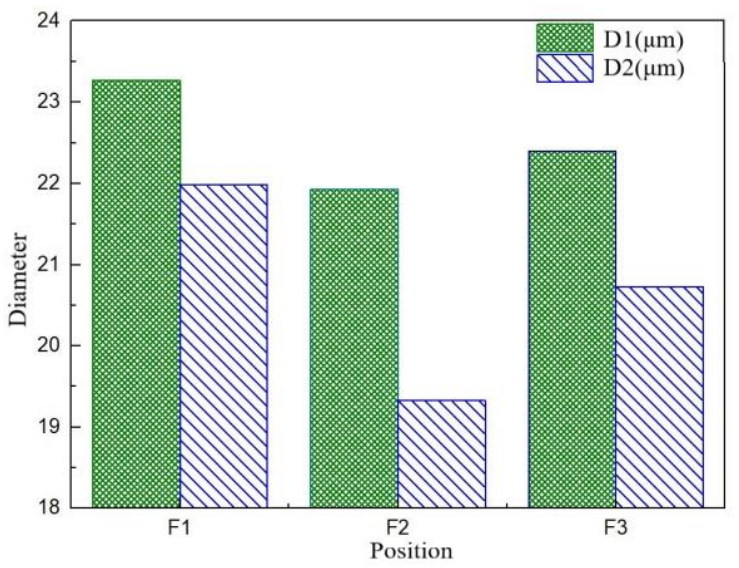

Fig. 12 Ferrite diameter under the two processes

In the metallurgical structure of the corner regions, the average grain diameters of the directly formed square tube are 19.61, 20.09, 20.49, and 20.01 $\mu \mathrm{m}$, whereas those of the continuously formed tube are 19.63, 18.81, 18.49, and $19.26 \mu \mathrm{m}$. Compared with the directly formed tube, the grain size of the continuously formed tube is smaller because in the continuous forming process, the sheet material is first formed into a round tube and then shaped into a square tube. Thus, the corner region undergoes two rounds of external tension and internal pressure. The grains produce a subtle difference, the massive ferrite becomes smaller, and the number of pearlite grains increases during the extrusion process. This result confirms that in the tensile test, the continuously formed tubes have larger yield and ultimate strengths than the directly formed tubes.

\subsection{Difference in the residual stress from the two processes}

The continuously and directly formed specimens are measured using the hole-drilling method to find the transverse, longitudinal, and equivalent residual stresses. The positions where the measurements are recorded are shown in Fig. 13. The experimental setup used to test the square tube specimens is shown in 
Fig. 14.

The deformation during the direct forming is concentrated at the corners. However, the flat region is also involved in the deformation during the continuous forming, which causes further residual stress in this region. Fig. 15 shows the distribution of the equivalent residual stress. The residual stress distribution has a large stress gradient due to the cold forming and welding effects. The residual stress at the weld seam is significantly higher than at other locations, and the equivalent residual stress near the weld seam exhibits a decreasing gradient because the heat from welding causes localized expansion, which is taken up by either of the molten metals. Because of the constraints from the far part of the weld zone, when the weld cools, some areas cool and contract more than the others, leaving residual stresses.

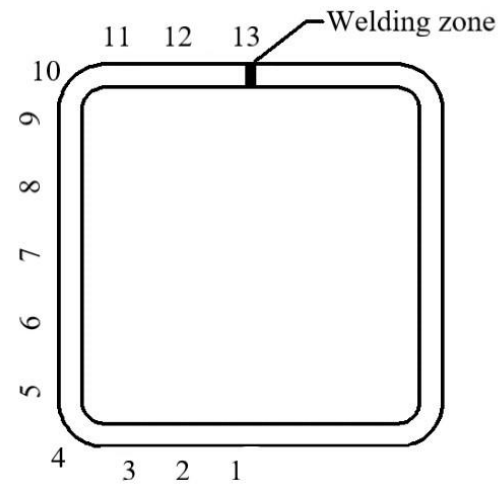

Fig. 13 Positions of the residual stress measurements

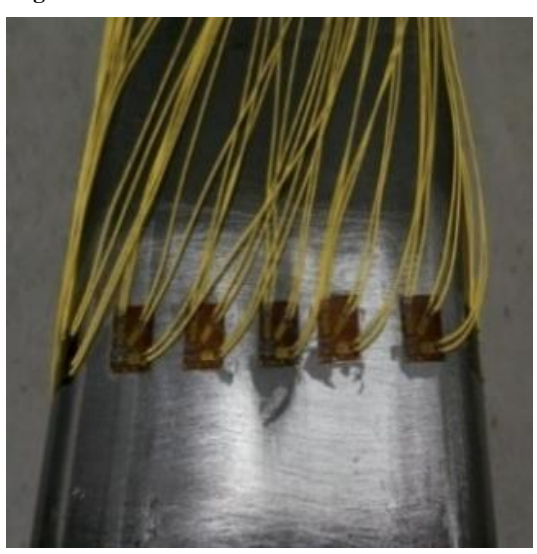

Fig. 14 Experimental setup for the residual-stress measurements

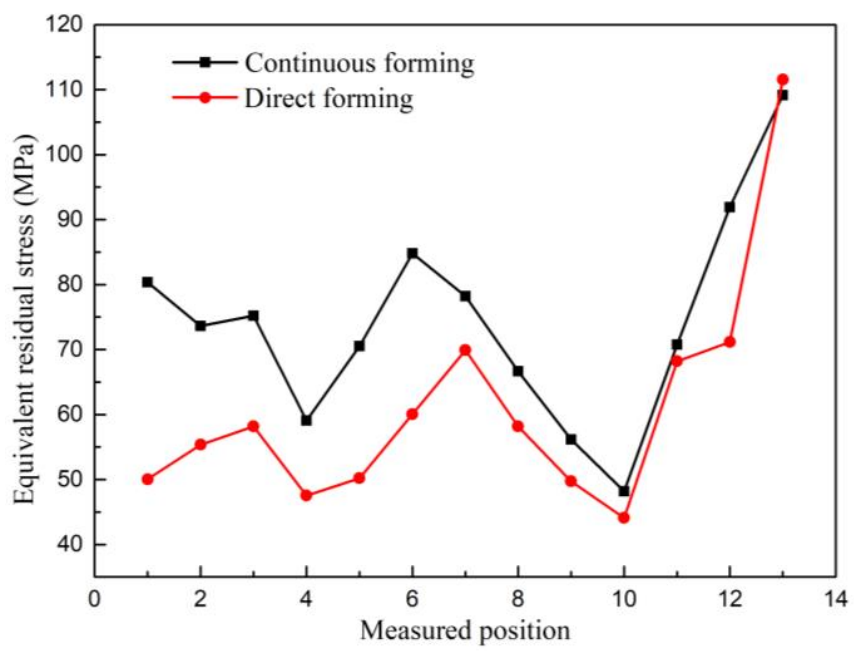

Fig. 15 Residual stress from continuous and direct forming

The distribution of the horizontal residual stress is shown in Fig. 16. Under different processing techniques, the stress distribution trend is the same. At the same position, the stress from continuous forming is higher than that from direct forming. The stress is lower in the corner region than that in the flat region, and all the values are small, indicating that both processing techniques exert only a small effect on the horizontal residual stress.

The distribution of the longitudinal residual stress is shown in Fig. 17. The trend that describes the longitudinal residual stress distribution is not obvious. In general, the longitudinal residual stress from the continuous forming is higher than that from the direct forming, which indicates that roll forming causes both longitudinal and horizontal deformation. The longitudinal strain is affected by more factors, and the processing is more complicated. The differences in the deformation process indicate that the longitudinal residual stress is more complicated in the flat region of the continuously formed tube than that in the directly formed tube. The mean horizontal residual stress is similar in both cases, indicating that the forming process has a significant effect on the longitudinal residual stress and less influence on the horizontal residual stress. The residual stress from the continuous forming is also higher than that from the direct forming.

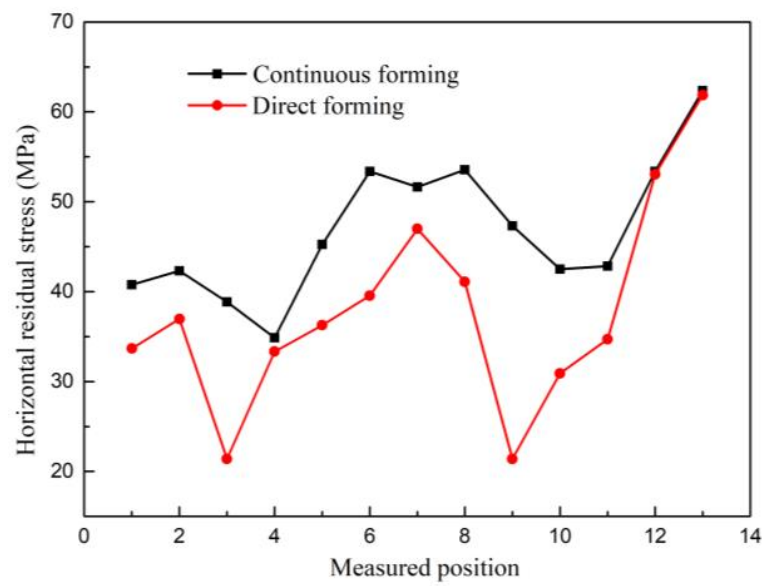

Fig. 16 Horizontal residual stress from continuous and direct forming

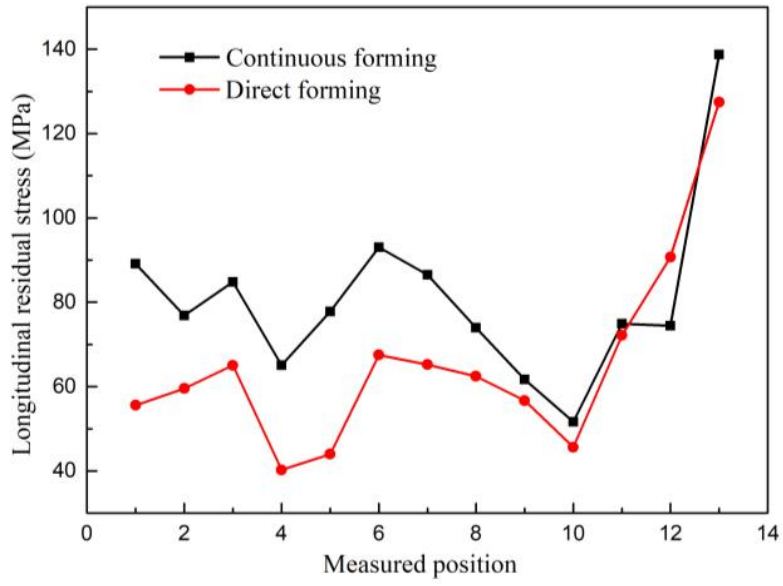

Fig. 17 Longitudinal residual stress from continuous and direct forming

\subsection{Differences in the microstructure of the welding seam between two processes}

The two processes result in welds with different material properties. The quality of the weld after the continuous forming is better than that after the direct forming. The main reason for this is that when the round tube is welded, a large pressing force is applied above the recrystallization temperature, which is equivalent to hot working in the weld zone. This force promotes recrystallization and refining of the grains in this region. Fig. 18 shows a stress cloud diagram of the FEA. The continuous forming welding pressure is greater than the direct forming welding pressure.

In addition to a larger press force being applied using the squeeze rolls, a large horizontal press force is produced by flattening the sections to make the welding edge fully pressed. Therefore, the range width of the continuously formed welding zones (50× magnification), which is shown in Fig. 19, is smaller than that in the direct forming. Fig. 19 shows the microstructure of the decarburized layer, which represents the overheated and recrystallized zone of the square tube weld of the two forming processes. Through the evolution of the cube elements in three zones, they represent the microstructure and change in the weld zone. 


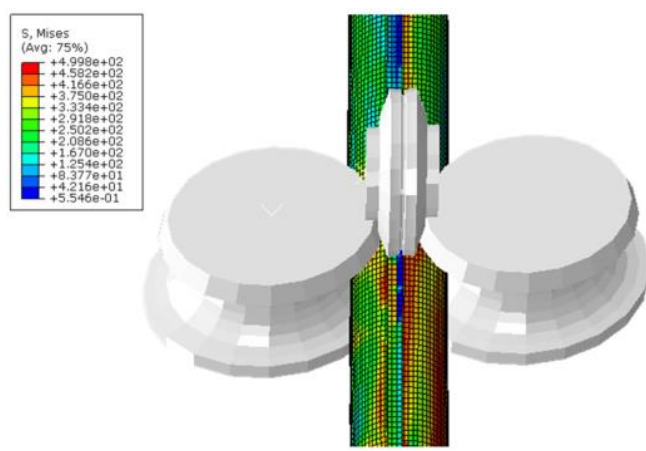

(a) Continuous forming

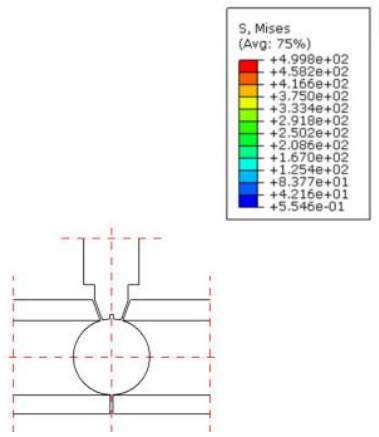

ig. 18 Stress contour and 2D roll profile of the squeeze rolls

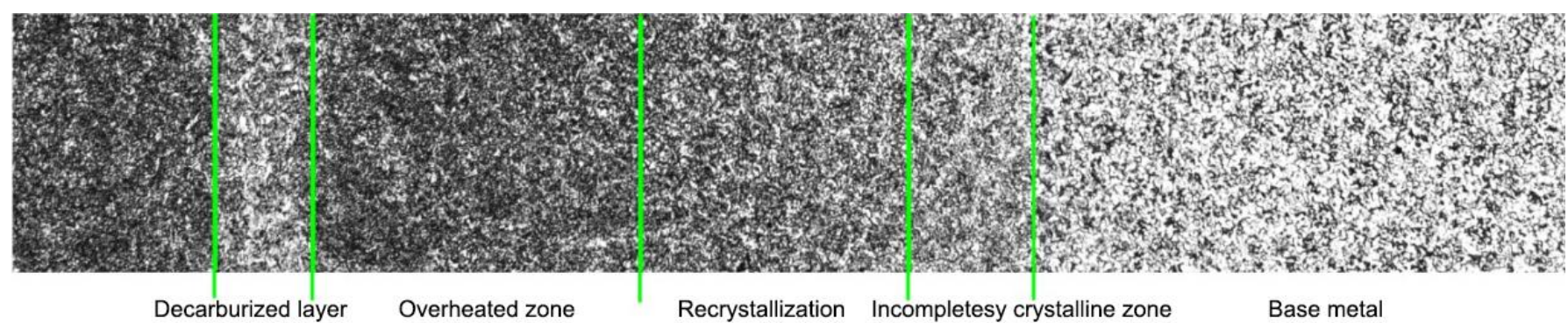

(a) Welding seam from continuous forming

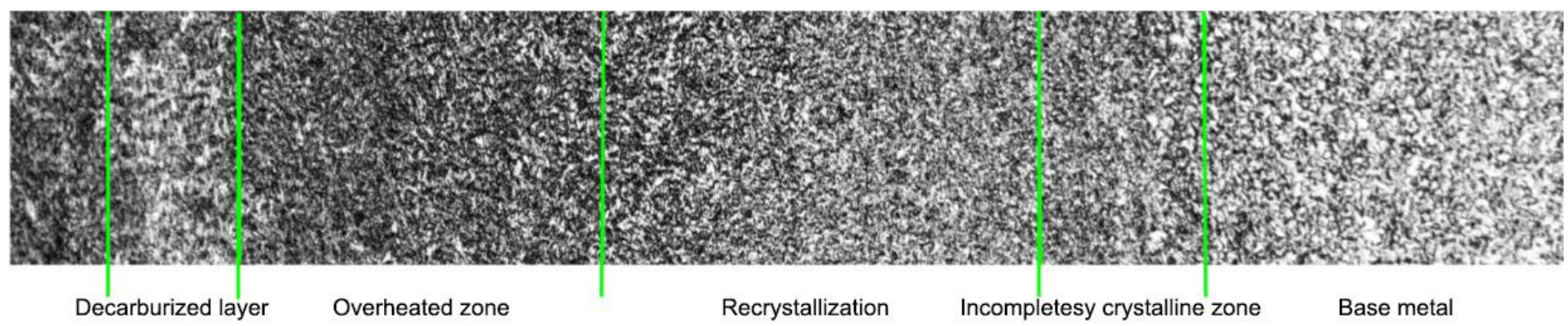

(b) Welding seam from direct forming

Fig. 19 Microstructure for each zone

Fig. 20 shows that that the Widmanstatten structure of the decarburized layer of the directly formed square tube is obviously more than that of the continuously formed square tube, and the grains are larger. Continuous forming uses round-tube welding, and large welding pressure is applied during the welding process. The tube welding end can be fully contacted, in contrast to that in the direct forming, which can effectively inhibit the growth of austenite grains. The existence of ferrite in the Widmanstatten forms a weak surface, which greatly reduces the plasticity and impact toughness of the material. In the microstructure analysis, fewer Widmanstatten structures are observed in the decarburized layer of the continuously formed specimen, and its plasticity and anti-impact toughness were better than those in the directly formed specimen.

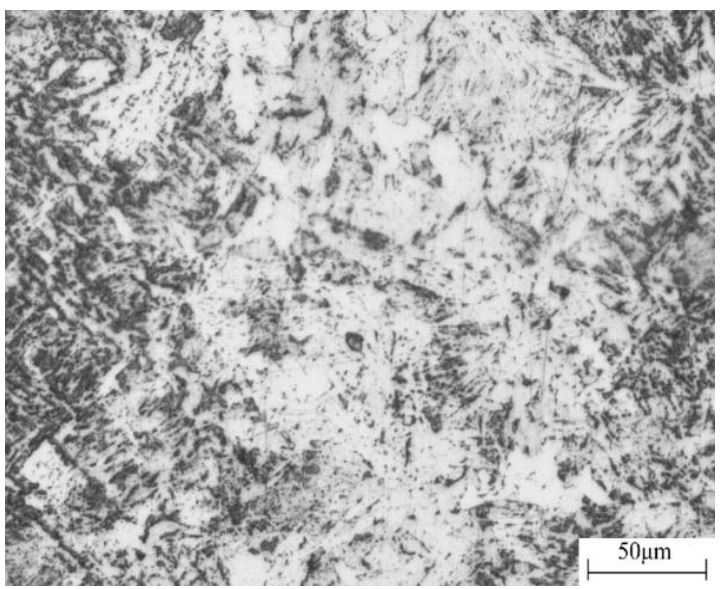

(a) Direct forming

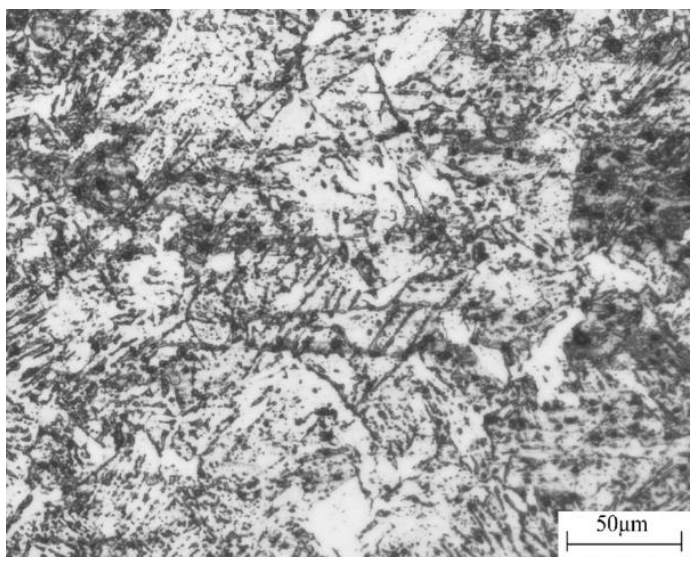

(b) Continuous forming

Fig. 20 Microstructure of the 200-times decarburized layer

When the overheating zone is welded, the temperature is in the range from below the solidus to $1200{ }^{\circ} \mathrm{C}$. Fig. 21 shows the metallographic structure of the superheated zone of the square tube in the two forming processes under a $200 \times$ light-magnification microscope. We can observe that the structure of the directly formed square-tube overheating zone contains more Widmanstatten structures and larger grains. There exist several Widmanstatten structures that contain ferrite in the decarburized layer and superheated zone, which directly lead to the low strength and poor toughness in the welding zone. 


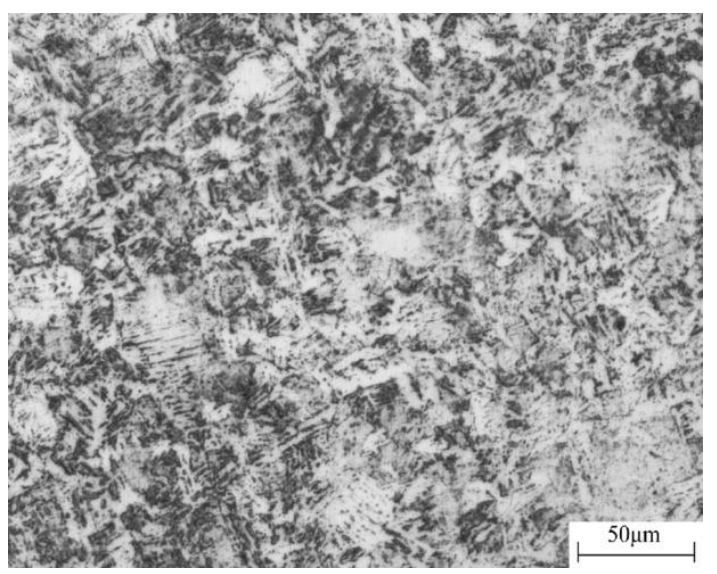

(a) Direct forming

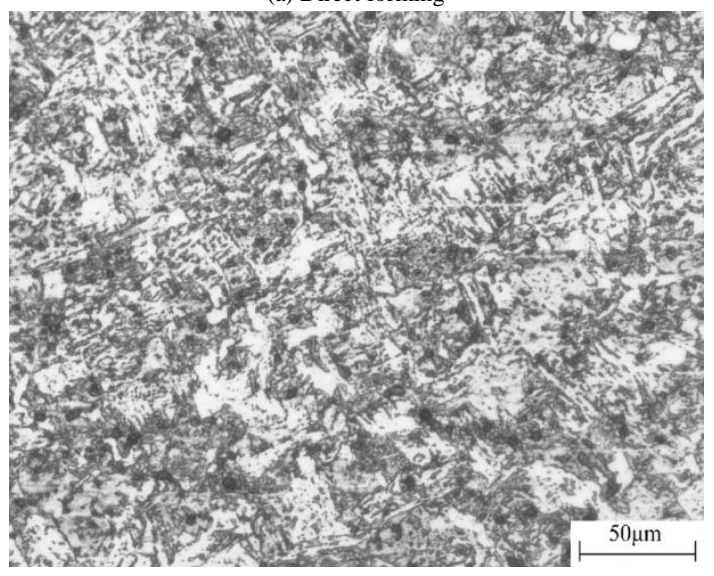

(b) Continuous forming

Fig. 21 Metallographic structure in the 200-times overheated zone

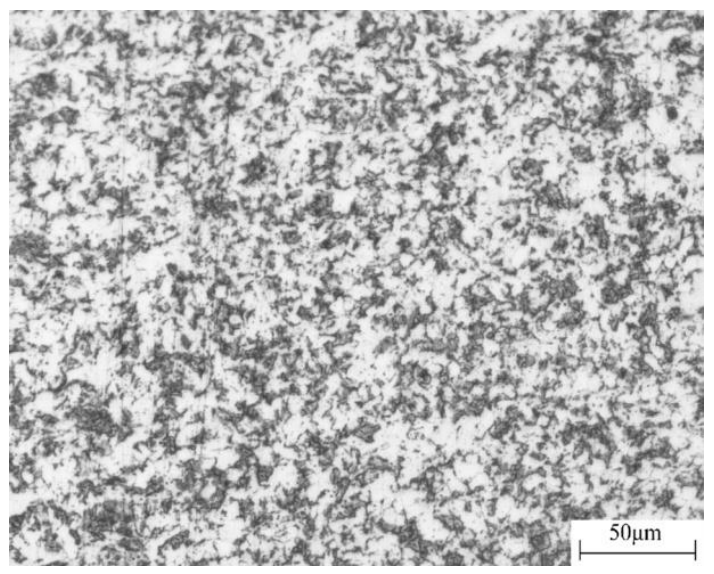

(a) Direct forming

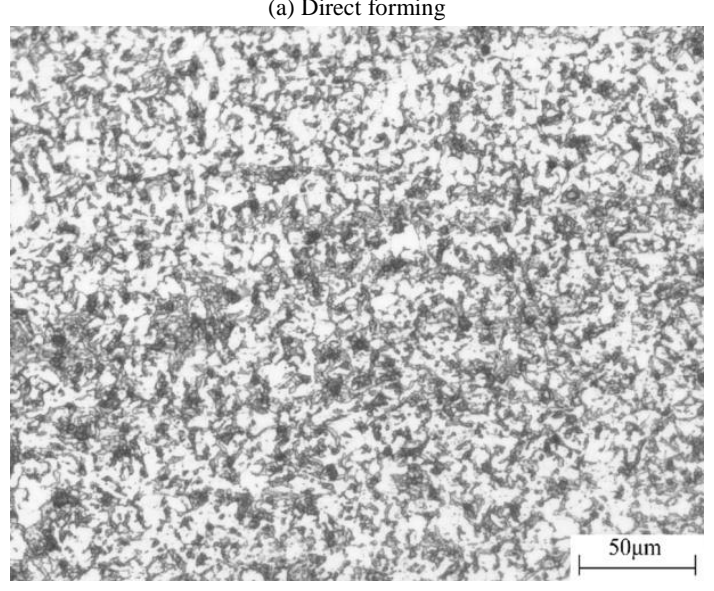

(b) Continuous forming

Fig. 22 Microstructure of the 200-times recrystallized zone

Fig. 22 shows the metallographic structure of the recrystallization zone in the direct and continuous forming square tube welding. We can observe the presence of a small amount of bainite grains besides the uniform and fine pearlite and ferrite in the structure. Thus, the strength and toughness of the materials in the recrystallization zone are better. Compared with those shown in Figs. 22(a) and (b), the pearlite and ferrite in the recrystallization zone in the continuously formed specimen are obviously more uniform and finer, and more pearlite grains are present. The overall performance of the continuously formed square tube in this area is better. It has not only a higher yield strength but also better toughness. Because of the effect of recrystallization, the strength and toughness of this zone in the square tube in both forming processes are better than those of the base material.

\section{Conclusions}

In this study, tensile tests, metallography, and residual stress measurements were performed on square tubes made by two forming processes. Furthermore, finite element models were set up using ABAQUS. The behavior of the directly and continuously formed tubes was described. The main research findings and conclusions are as follows.

(1) Compared with that in the base material, the strength of the flat and corner regions in both tubes had improved, and the strength in the corner regions was greater than that in the flat regions. The yield and ultimate strengths of each part of the continuously formed square tube were higher than those of the directly formed square tube. However, the roll forming effect produced by the two forming processes reduced the elongation of the square tube. The greater the roll forming effect, more obvious was the reduction in elongation.

(2) FEA demonstrated that the largest difference in plastic strain occurred in the flat regions. The strain histories were different at the corners, but the final strains were similar. The residual stress showed that different processes had an obvious effect on the longitudinal residual stress and lesser effect on the horizontal residual stress. The residual stress from continuous forming was higher than that from direct forming.

(3) The microstructure in the corner regions of both tubes were similar, and more differences occurred in the flat regions. The grains in the flat and corners regions of the continuously formed square tube were more uniform and finer than those of the directly formed square tube, and the mechanical properties were better.

(4) Weld-seam metallographic experiments were implemented. The microscopic tests indicated that the weld seam of the continuously formed square tube had greater plasticity and anti-impact toughness than the directly formed square tube.

\section{Acknowledgements}

The authors are grateful to the National Natural Science Foundation of China (No.51074204), Beijing Municipal Education Commission Project of “Great Wall Scholar"Program (No. CIT\&TCD20190306), and the Project of Beijing Municipal Natural Science and Beijing Municipal Education Commission Jointly Fundation (No. KZ201910009011) for their financial supports. Also, thanks are given to the High-level Featured Disciplines Development Project of North China University of Technology (2020-2025) and Yujie Talent Support Program of North China University of Technology (No. 18XN154-005).

\section{References}

[1] Huang Y. and Young B., "The art of coupon tests”, Journal of Constructional Steel Research, 96(6), 159-175, 2014

[2] Kohar C.P., Mohammadi M., Mishra R.K. and Inal K., "Effects of elastic-plastic behaviour on the axial crush response of square tubes", Thin-Walled Structures, 93, 64-87, 2015.

[3] Hu S.D., Ye B. and Li L.X., "Materials properties of thick-wall cold-rolled welded tube with a rectangular or square hollow section", Construction and Building Materials, 25, 2683-2689, 2011.

[4] Sun M. and Packer J.A., "Direct-formed and continuous-formed rectangular hollow sectionscomparison of static properties", Journal of Constructional Steel Research, 92, 67-78, 2014.

[5] Li G.W. and Li Y.Q., "Overall stability behavior of axially compressed cold-formed thickwalled steel tubes", Thin-Walled Structures, 125, 234-244, 2018.

[6] Li H.T. and Young B., "Material properties of cold-formed high strength steel at elevated temperatures", Thin-Walled Structures, 115, 289-299, 2017.

[7] Davani R.K.Z., Miresmaeili R. and Soltanmohammadi M., "Effect of thermomechanical parameters on mechanical properties of base metal and heat affected zone of X65 pipeline steel weld in the presence of hydrogen", Materials Science and Engineering: A, 718, 135-146, 2018.

[8] Pham T.H. and Kim S.E., "Nanoindentation for investigation of microstructural composition in SM490 steel weld zone”, Journal of Constructional Steel Research, 110, 40-47, 2015

[9] Luo X., Niu Y.W., Chen X.H., Tang H. and Wang Z.D., "High performance in base metal and CGHAZ for ferrite-pearlite steels", Journal of Materials Processing Technology, 242, 101109, 2017.

[10] Miura T., Ueji R., Fujii H., Komine H. and Yanagimoto J., "Stabilization of austenite in low carbon $\mathrm{Cr}-\mathrm{Mo}$ steel by high speed deformation during friction stir welding", Materials \& 
Design, 90, 915-921, 2016

[11] Shokrieh M.M., Jalili S.M. and Kamangar M.A., "An eigen-strain approach on the estimation of non-uniform residual stress distribution using incremental hole-drilling and slitting techniques", International Journal of Mechanical Sciences, 148, 383-392, 2018.

[12] Li G.W., Li Y.Q., Xu J. and Cao X., "Experimental investigation on the longitudinal residual stress of cold-formed thick-walled SHS and RHS steel tubes", Thin-Walled Structures, 138, 473-484, 2019.

[13] Acevedo C., Nussbaumer A. and Drezet J.M., "Evaluation of residual welding stresses and fatigue crack behavior in tubular K-joints in compression", Stahlbau, 80(7), 483-491, 2011.

[14] Ma J.L., Chan T.M. and Young B., "Material properties and residual stresses of cold-formed high strength steel hollow sections" Journal of Constructional Steel Research, 109, 152-165, 2015.

[15] Li G.W., Li Y.Q., Xi J. and Cao X., "Experimental investigation on the longitudinal residual stress of cold-formed thick-walled SHS and RHS steel tubes", Thin-Walled Structures, 138, 473-483, 2015

[16] Liu X. and Chung K.F., "Experimental and numerical investigation into temperature histories and residual stress distributions of high strength steel S690 welded H-sections", Engineering Structures, 165, 396-411, 2018.

[17] Yao Y., Quach W.M. and Young B., "Finite element-based method for residual stresses and plastic strains in cold-formed steel hollow sections", Engineering Structures, 188, 24-42, 2019

[18] Wen B.C. and Pick R.J., "Modelling of skelp edge instabilities in the roll forming of ERW pipe", Journal of Materials Processing Technology, 41(4), 425-446, 1994.

[19] Li S.H., Zeng G., Ma Y.F., Guo Y.J. and Lai X.M., "Residual stresses in roll-formed square hollow sections", Thin-Walled Structures, 47(5), 505-513, 2009.

[20] Ye Y., Zhang S.J., Han L.H. and Liu Y., "Square concrete-filled stainless steel/carbon steel bimetallic tubular stub columns under axial compression", Journal of Constructional Steel Research, 146, 49-62, 2018.

[21] Yuan F., Huang H. and Chen M.C., "Effect of stiffeners on the eccentric compression behaviour of square concrete-filled steel tubular columns", Thin-Walled Structures, 135, 196209, 2019

[22] Yang Z.Y., Zhao C.C., Dong G.J., Du B. and Zhang L., "Analytical model of corner filling with granular media to investigate the friction effect between tube and media", International Journal of Advanced Manufacturing Technology, 99, 211-224, 2018.

[23] Amraei M., Jiao H., Zhao X.L. and Tong L.W., "Fatigue testing of butt-welded high strength square hollow sections strengthened with CFRP", Thin-Walled Structures, 120, 260-268, 2017 